Published in final edited form as:

Glob Heart. 2015 December ; 10(4): 337-340. doi:10.1016/j.gheart.2015.04.001.

\title{
DS-Connect ${ }^{\mathrm{TM}}$ : A Promising Tool to Improve Lives and Engage Down Syndrome Communities Worldwide
}

\author{
Emmanuel Peprah, Ph.D., \\ Center for Translational Research and Implementation Science, National Heart, Lung, and Blood \\ Institute, National Institutes of Health, 6701 Rockledge Dr. Bethesda, MD 20892, Phone: \\ 301-451-9873

\begin{abstract}
Melissa A. Parisi, M.D., Ph.D. [Branch Chief], Intellectual and Developmental Disabilities Branch, Eunice Shriver Kennedy National Institute for Child Health and Human Development, National Institutes of Health, 6100 Executive Blvd, Rm 4B09G, Bethesda, MD 20892
\end{abstract}

Lisa Kaeser, J.D. [Director],

Office of Legislation and Public Policy, Eunice Shriver Kennedy National Institute for Child Health and Human Development, National Institutes of Health, 31 Center Drive, Room 2A03, Bethesda, MD 20892-2425

\section{Sujata Bardhan, Ph.D., Intellectual and Developmental Disabilities Branch, Eunice Shriver Kennedy National Institute for Child Health and Human Development, National Institutes of Health, 6100 Executive Blvd, Bethesda, MD 20892 \\ MaryLou Oster-Granite, Ph.D., and Intellectual and Developmental Disabilities Branch, Eunice Shriver Kennedy National Institute for Child Health and Human Development, National Institutes of Health, 6100 Executive Blvd, Bethesda, MD 20892 \\ Yvonne T. Maddox, Ph.D. [Acting Director] \\ National Institute on Minority Health and Health Disparities, Former Deputy Director, National Institute of Child Health and Human Development, National Institutes of Health, 6707 Democracy Boulevard, Suite 800, Bethesda, MD 20892-5465 \\ Emmanuel Peprah: peprahek@mail.nih.gov}

\footnotetext{
Correspondence to: Emmanuel Peprah, peprahek@mail.nih.gov.

Publisher's Disclaimer: This is a PDF file of an unedited manuscript that has been accepted for publication. As a service to our customers we are providing this early version of the manuscript. The manuscript will undergo copyediting, typesetting, and review of the resulting proof before it is published in its final citable form. Please note that during the production process errors may be discovered which could affect the content, and all legal disclaimers that apply to the journal pertain.

Competing Interests

The authors declare that they do not have any competing interests.

Author Contributions

EP developed the manuscript; MP provided significant intellectual input, MOG provided data and significant intellectual input SB provided significant intellectual input, LK provided significant intellectual input, YM spearheaded the activity and provided significant intellectual input
} 


\section{Abstract}

Down syndrome (DS) is the most common genetic cause of intellectual and developmental disabilities (IDDs) in the United States with an estimated birth prevalence of 1:691 births (http:// www.cdc.gov/ncbddd/birthdefects/data.html); however, worldwide estimates of the number of individuals with IDDs, including DS, remain speculative. Little is known about the global health impact of DS, such as heart defects, gastrointestinal malformations, and other medical and behavioral issues. Further research is needed to develop the next generation of novel therapies and compounds aimed at improving cognition, reducing dementia and mitigating other manifestations of DS. To address these challenges, the National Institutes of Health (NIH) has created the first web-based, voluntary registry and data resource called DS-Connect ${ }^{\mathrm{TM}}$ : The Down Syndrome Registry (https://DSConnect.nih.gov) to collect demographic and health information about individuals with DS.

\section{Keywords}

Down syndrome; Trisomy 21; registry; heart defects; global health research

\section{Opportunities in DS Research}

Over the past several decades, families affected by both rare and common conditions have come to appreciate the value of systematic registries to document the natural history of the condition and to provide opportunities to participate in ongoing medical and social science research. Although Down syndrome (DS) is the most common genetic cause of intellectual and developmental disabilities (IDDs) in the United States, worldwide estimates of the number of individuals with IDDs such as DS remain speculative at best ${ }^{1}$ (see Figure 1). Furthermore, little is known about the global impact of the other non-IDD manifestations of DS that are caused by having three copies of chromosome 21, such as heart defects, gastrointestinal malformations, and the other medical and behavioral issues.

In the last 40 years, substantial research has occurred to better elucidate the molecular underpinnings of DS and the resulting clinical consequences ${ }^{2}$. Specialized medical interventions (e.g., pediatric heart surgery and antibiotics) have improved early survival and longevity for many people with DS in the United States and Europe ${ }^{3-5}$. A wide spectrum of biomedical and educational research has led to the development of specialized medical and educational programs that have arguably had a profound and positive impact on the quality of life for people with DS and their families ${ }^{6-8}$. However, many challenges still remain. Adults with DS are hospitalized more than the general population and for longer durations ${ }^{9}$. Approximately $50 \%$ of those with DS have some form of congenital heart disease, with atrioventricular septal defects constituting a significant proportion. Moreover, a high prevalence of celiac disease and autoimmune conditions was observed in older individuals. Also, those with DS in their 30s and 40s are known to be at significant risk for the earlyonset of Alzheimer's disease, perhaps due to the triplicate copy of $\beta$-amyloid precursor protein on chromosome 21. These phenotypic presentations of DS are under intense investigation by researchers using various tools including animal models (e.g. trisomic mice) in hopes of developing novel therapies to ameliorate those impairments. However, mice are 
not equivalent to humans, and most testing paradigms do not capture the complexities of human cognition and behavior ${ }^{10}$. Moreover, many treatments effective in improving working memory in mice have not translated to humans ${ }^{11}$, and relatively few cognitionenhancing pharmaceutical therapies have been tested in humans. The U.S. National Institutes of Health (NIH) has recognized the need to promote research that can benefit individuals with DS by informing the development of novel therapies and compounds to improve cognition, reduce dementia and mitigate the other manifestations of DS.

\section{DS-Connect ${ }^{\mathrm{TM}}$ : The Down Syndrome Registry}

To address these challenges, the NIH has created the first web-based, voluntary registry and data resource for DS called DS-Connect ${ }^{\mathrm{TM}}$ : The Down Syndrome Registry (http://

DSConnect.nih.gov) to collect demographic and health information about individuals with DS. Since the launch of the registry in September 2013, over 2800 participants registered, mostly in the U.S. All of the information in this secure registry is entered by an individual with DS or a family member after an online consent process, and can be updated periodically. Notably, the de-identified, aggregate data can be viewed by registry participants as well as registered professionals; the professional portal was launched in fall 2014 and is open to interested researchers, clinicians, advocates, and industry representatives. One feature of the registry is that a researcher will be able to apply for assistance in recruiting subjects with DS for clinical studies--once the investigator's study is approved, the registry coordinator will contact eligible families to inform them of the study and invite them to contact the researcher directly to participate in the research. This provides a targeted mechanism to recruit individuals with specific manifestations for clinical trials via DS-Connect ${ }^{\mathrm{TM}}$ while maintaining participant confidentiality, since scientists and researchers will never have direct access to the registrants. DS-Connect ${ }^{\mathrm{TM}}$ will also be an essential tool for obtaining self-reported medical information from individuals and families throughout the lifespan, which can create a better understanding of the natural history of DS and hence, enable the design of better therapeutic interventions and treatments tailored to different phases of development. The information in DS-Connect ${ }^{\mathrm{TM}}$ could also be used to comprehend disparities in health outcomes for those with DS both within the United States and internationally. Participation by a global cohort of individuals in DS-Connect ${ }^{\mathrm{TM}}$ could facilitate longitudinal studies of many aspects of DS and enrich geographic and racial/ ethnicity data, while promoting clinical research that will improve the health and quality of life for individuals with DS.

In addition, the NIH is addressing ongoing challenges in DS research by engaging in continued dialogue with the broader DS community. The NIH published the first national research agenda for DS, the NIH Research Plan on Down Syndrome, in 2007 after inviting comments from researchers, clinicians, advocates, and families across the U.S. ${ }^{12}$ In 2011, the NIH brought together national and international DS organizations in the creation of a public-private partnership, aptly named the Down Syndrome Consortium, with the goal of advancing DS research. Consortium members and other interested parties provided rich commentary on the NIH Research Plan on Down Syndrome, which led to an updated research agenda. This current plan addresses needs articulated by the DS research community in five major areas: Pathophysiology of Down Syndrome and Disease 
Progression; Screening, Diagnosis, and Functional Measures of Down Syndrome-Related Conditions; Treatment and Management; Down Syndrome and Aging; and Research Infrastructure. This updated plan outlines priority areas and can be used as a roadmap to support promising DS research in the future. ${ }^{13}$

\section{Conclusion}

By tapping into the collective voice of individuals and families using DS-Connect ${ }^{\mathrm{TM}}$, the global DS community, researchers and caregivers will improve our understanding of this condition throughout the lifespan of affected individuals and enhance research participation globally. Along with a clear research agenda as articulated in the 2014 NIH Research Plan on Down Syndrome, ${ }^{13} \mathrm{NIH}$ is working to create the tools and resources to support a global research effort to improve the quality of life for those with DS,; furthermore, the success with this approach could galvanize research across all IDD and other rare genetic diseases, and thus help improve the lives of a broad range of affected individuals worldwide.

\section{Acknowledgements}

The authors would like to thank Vesna Kutlesic for providing significant discussions in regards to shaping the manuscript.

\section{List of Abbreviations}

$\begin{array}{ll}\text { DS } & \text { Down syndrome } \\ \text { IDDs } & \text { Intellectual and developmental disabilities } \\ \text { NIH } & \text { National Institutes of Health }\end{array}$

\section{References}

1. World Health Organization., World Bank. World report on disability. Geneva: World Health Organization; 2011.

2. Sherman SL, Allen EG, Bean LH, Freeman SB. Epidemiology of down syndrome. Mental retardation and developmental disabilities research reviews. 2007; 13:221-227. [PubMed: 17910090]

3. Yang Q, Rasmussen SA, Friedman JM. Mortality associated with down's syndrome in the USA from 1983 to 1997: A population-based study. Lancet. 2002; 359:1019-1025. [PubMed: 11937181]

4. Cocchi G, Gualdi S, Bower C, Halliday J, Jonsson B, Myrelid A, Mastroiacovo P, Amar E, Bakker MK, Correa A, Doray B, Melve KK, Koshnood B, Landau D, Mutchinick OM, Pierini A, Ritvanen A, Ruddock V, Scarano G, Sibbald B, Sipek A, Tenconi R, Tucker D, Anneren G. International trends of down syndrome 1993-2004: Births in relation to maternal age and terminations of pregnancies. Birth defects research. Part A, Clinical and molecular teratology. 2010; 88:474-479.

5. Englund A, Jonsson B, Zander CS, Gustafsson J, Anneren G. Changes in mortality and causes of death in the swedish down syndrome population. American journal of medical genetics. Part A. 2013; 161A:642-649. [PubMed: 23436430]

6. Health supervision for children with down syndrome. American academy of pediatrics committee on genetics. Pediatrics. 1994; 93:855-859. [PubMed: 8165098]

7. Bull MJ, Committee on G. Health supervision for children with down syndrome. Pediatrics. 2011; 128:393-406. [PubMed: 21788214]

8. International review of research in mental retardation. 2010. 
9. Tenenbaum A, Chavkin M, Wexler ID, Korem M, Shulman C, Merrick J. Morbidity and hospitalization of adults with down syndrome. J Intell Disabil Res. 2012; 56:753-753.

10. Underwood E. Can down syndrome be treated? Science. 2014; 343:964-967. [PubMed: 24578561]

11. Costa AC, Scott-McKean JJ. Prospects for improving brain function in individuals with down syndrome. CNS drugs. 2013; 27:679-702. [PubMed: 23821040]

12. The National Institutes of Health. National Institutes of Health Research Plan on Down Syndrome. 2007. (https://www.Nichd.Nih.Gov/publications/pubs/documents/dsresearchplan_2007.Pdf).

13. The National Institutes of Health. Down syndrome Directionsl The National Institutes of Health Research Plan on Down Syndrome. 2014. (http://www.Nichd.Nih.Gov/publications/pubs/ documents/dsresearchplan_2014.Pdf).

14. Miao ZY, Liu X, Shi TK, Xu Y, Song QH, Tang SH. First trimester, second trimester, and integrated screening for down's syndrome in china. J Med Screen. 2012; 19:68-71. [PubMed: 22653574]

15. Sipek A Jr, Gergor V, Sipek A, Horacek J, Langhammer P. Recent results of prenatal diagnosis in the czech republic. EUROCAT Registry Leaders Meeting. 2012

16. Irving CA, Chaudhari MP. Cardiovascular abnormalities in down's syndrome: Spectrum, management and survival over 22 years. Arch Dis Child. 2012; 97:326-330. [PubMed: 21835834]

17. Marttala J, Yliniemi O, Gissler M, Nieminen P, Ryynanen M. Prevalence of down's syndrome in a pregnant population in finland. Acta Obstet Gyn Scan. 2010; 89:715-717.

18. Rousseau T, Ferdynus C, Thauvin-Robinet C, Gouyon JB, Sagot P. Impact of maternal age distribution on the expected live birth prevalence of down's syndrome in the metropolitan france between 1965 and 2008. J Gynecol Obst Bio R. 2010; 39:284-289.

19. Rousseau T, Amar E, Ferdynus C, Thauvin-Robinet C, Gouyon JB, Sagot P. Variations in the prevalence of down's syndrome in the french population between 1978 and 2005. J Gynecol Obst Bio R. 2010; 39:290-296.

20. Cocchi G, Gualdi S, Bower C, Halliday J, Jonsson B, Myrelid A, Mastroiacovo P, Amar E, Bakker MK, Correa A, Doray B, Melve KK, Koshnood B, Landau D, Mutchinick OM, Pierini A, Ritvanen A, Ruddock V, Scarano G, Sibbald B, Sipek A, Tenconi R, Tucker D, Anneren G. International trends of down syndrome 1993-2004: Births in relation to maternal age and terminations of pregnancies. Birth Defects Res A. 2010; 88:474-479.

21. Luthgens K, Abele H, Alkier R, Hoopmann M, Kagan KO. [cross-validation of the first trimester screening algorithm of the fmf london on 38,700 pregnancies in germany]. Ultraschall in der Medizin. 2011; 32:367-372. [PubMed: 21667432]

22. Kaur G, Srivastav J, Kaur A, Huria A, Goel P, Kaur R, Kataria S, Chavan BS, Kochhar S, Aggarwal P, Kaur N, Panigrahi I, Chawla P. Maternal serum second trimester screening for chromosomal disorders and neural tube defects in a government hospital of north india. Prenatal diagnosis. 2012; 32:1192-1196. [PubMed: 23055346]

23. Hoe TS, Boo NY, Clyde MM. Incidence of down's syndrome in a large malaysian maternity hospital over an 18 month period. Singapore medical journal. 1989; 30:246-248. [PubMed: 2531468]

24. Noraihan MN, See MH, Raja R, Baskaran TP, Symonds EM. Audit of birth defects in 34,109 deliveries in a tertiary referral center. The Medical journal of Malaysia. 2005; 60:460-468. [PubMed: 16570708]

25. Zlotogora JL, Haklai Z, Leventhal A. Utilization of prenatal diagnosis and termination of pregnancies for the prevention of down syndrome in israel. Israel Med Assoc J. 2007; 9:600-602.

26. Merrick J. Incidence and mortality of down syndrome. Israel Med Assoc J. 2000; 2:25-26.

27. Kazaura MR, Lie RT. Down's syndrome and paternal age in norway. Paediatr Perinat Ep. 2002; 16:314-319.

28. Offerdal K, Blaas HGK, Eik-Nes SH. Prenatal detection of trisomy 21 by second-trimester ultrasound examination and maternal age in a non-selected population of 49314 births in norway. Ultrasound Obst Gyn. 2008; 32:493-500.

29. Melve KK, Lie RT, Skjaerven R, Van Der Hagen CB, Gradek GA, Jonsrud C, Braathen GJ, Irgens LM. Registration of down syndrome in the medical birth registry of norway: Validity and time trends. Acta Obstet Gyn Scan. 2008; 87:824-830. 
30. Kovaleva NV, Butomo IV, Verlinskaia DK, Il'iashenko TN, Davidenkova EF. [increase in the incidence and risk of birth of children with down's syndrome in leningrad (1982-1989)]. Genetika. 1994; 30:265-270. [PubMed: 8045388]

31. Krikunova NI, Minaicheva LI, Nazarenko LP, Tadinova VN, Nesterova VV, Fadyushina SV, Shapran NV. Epidemiology of congenital malformations in gorno-altaisk, altai republic, russia. Russ J Genet+. 2004; 40:932-937.

32. Presson AP, Partyka G, Jensen KM, Devine OJ, Rasmussen SA, McCabe LL, McCabe ER. Current estimate of down syndrome population prevalence in the united states. The Journal of pediatrics. 2013; 163:1163-1168. [PubMed: 23885965] 


\section{Highlights}

- Down syndrome (DS) is the most common genetic cause of intellectual and developmental disabilities however, worldwide estimates remain speculative

- Little is known about the global health impact of DS, such as heart defects, gastrointestinal malformations, and other medical and behavioral issues

- To address these challenges, the National Institutes of Health has created the first web-based, voluntary registry and data resource called $D S$-Connect ${ }^{\mathrm{TM}}$ : The Down Syndrome Registry (https://DSConnect.nih.gov) 
A

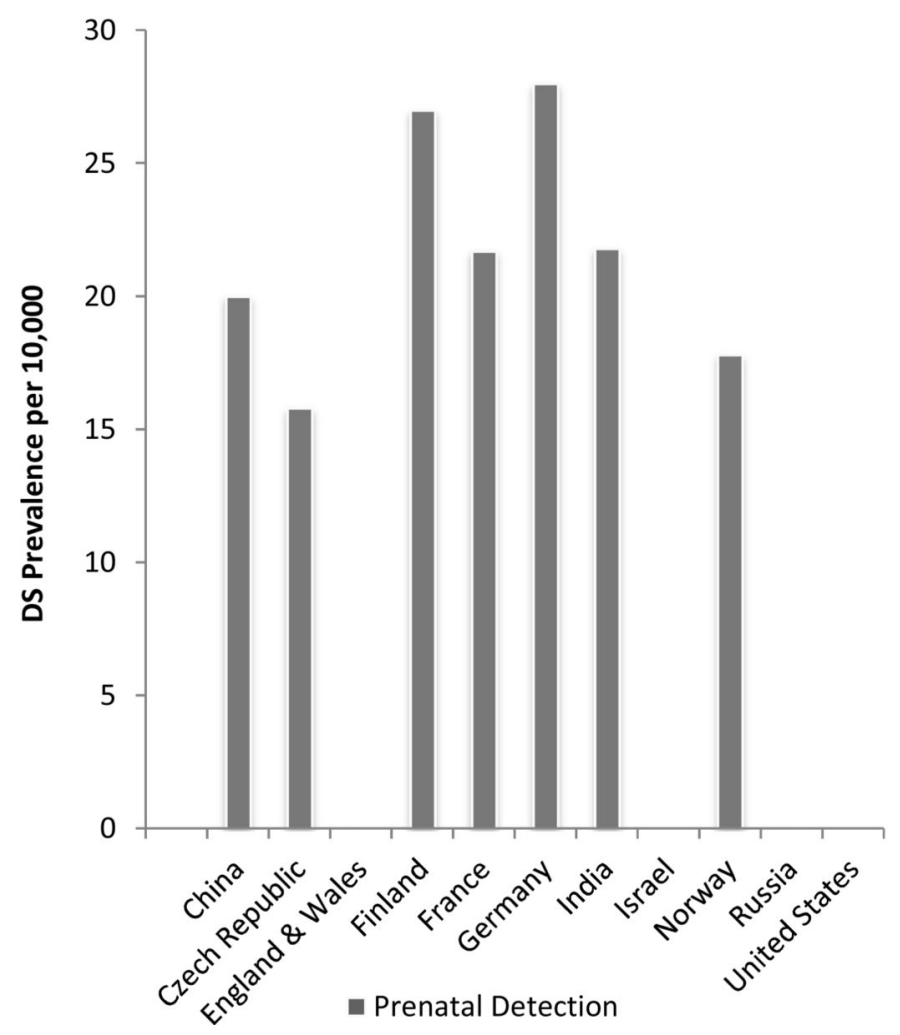

B

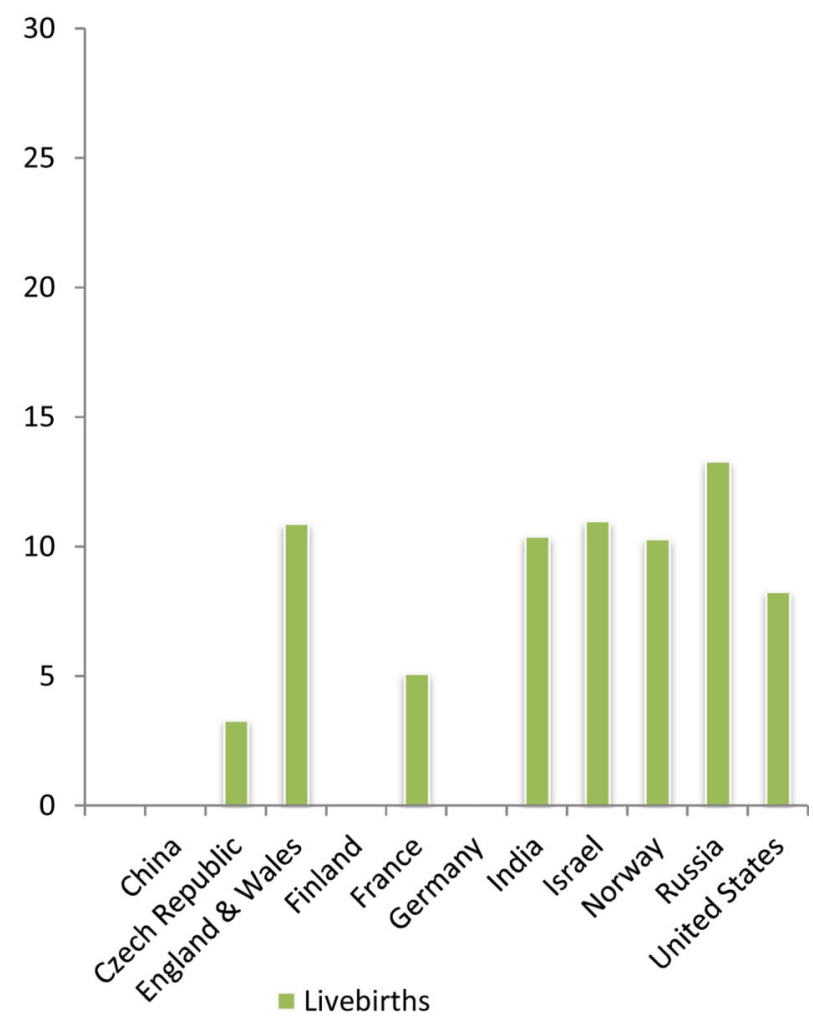

Figure 1.

Estimated global prevalence of Down Syndrome based on Prenatal diagnosis/detection (A) and Live births (B) per 10,000 in eleven countries. For 1A, data were not available for England \& Wales, Israel, Russia and the United States; for 1B, data were not available for China, Finland, and Germany.

China: The overall incidence was $1 / 520$ (see ref $^{14}$ );

Czech Republic: The total incidence including prenatal diagnostics was 1.58-22.2 but the total incidence per 10,000 births reported was 3.3-6.5 (see ref ${ }^{15}$ );

England and Wales: In UK the prevalence was found to be 1/917 (see ref ${ }^{16}$ )

Finland: The prevalence was found to be $1 / 370$ (see ref ${ }^{17}$ );

France: In France numbers vary from an expected live birth prevalence of 1/460 to a termination related decrease in live born prevalence to be $1 / 1960$ (see ref ${ }^{18,19}$ ) also the total prevalence of DS increased to 1/549 between 1993 to 2004, but the prevalence of DS births remained stable at $1 / 1205$ (see ref ${ }^{20}$ );

Germany: among singleton pregnancies the prevalence was $1 / 356$ (see ref ${ }^{21}$ );

India: Reports show a prevalence during pregnancy to be $1 / 451$ whereas in a maternity hospital in Kuala Lumpar the incidence of live births was 1/959 and in a tertiary referral center was $1 / 800$ (see ref ${ }^{22-24}$ )

Israel: Israel has a national program for the prevention of DS, however a majority of DS infants are born alive c.a. $1 / 1000$ (see ref ${ }^{25}$ ), in 1997 the actual incidence rate was 1/909 while the true incidence rate was $23.2\left(\right.$ see $\left.\mathrm{ref}^{26}\right)$; 
Norway: One study involving paternal age found a weak estimated effect and an incidence of $1 / 971$, another was $1 / 560$, a third study found a rate of $1 / 500$ amongst 288,213 births and terminations during 2001-200 (see ref ${ }^{27-29}$ );

Russia: Prevalence in Leningrad between 1982-1989 was 1/752 with a doubling of risk between ages 30-34 rather than 35-39, In, Altai Republic it was 1/1075 (see ref ${ }^{30,31}$ ); United States: A current estimate of prevalence is $1 / 1209$ (see ref ${ }^{32}$ ) 